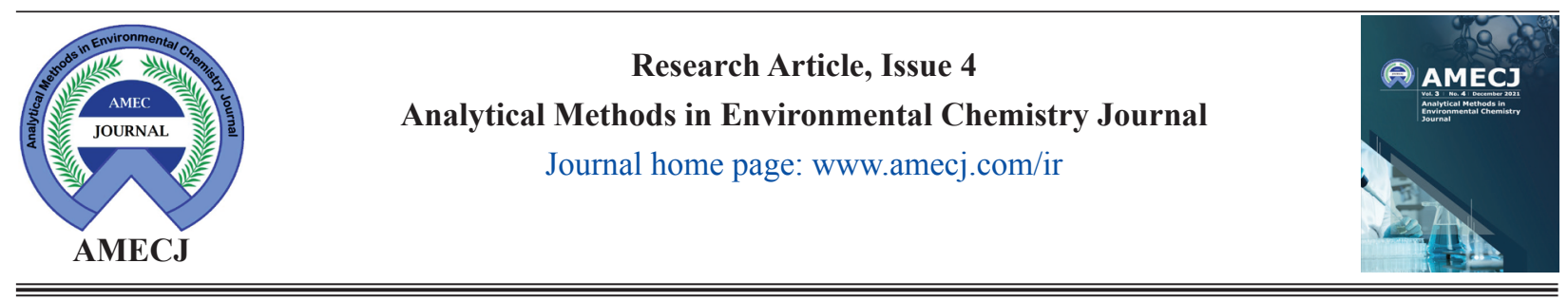

\title{
Adsorption of nitrate from aqueous solution with ZSM-5/Fe nanosorbent based on optimizing of the isotherms conditions before determination by UV-Vis Spectrophotometry
}

Mostafa Hassani ${ }^{a}$, Mohsen Zeeba,*, Amirhossein Monzavi ${ }^{\mathrm{b}}$, Zahra Khodadadi a and Mohammad Reza Kalaee

${ }^{a}$ Department of Applied Chemistry, Faculty of Science, Islamic Azad University, South Tehran Branch, Tehran, Iran

${ }^{b}$ Department of Polymer and Textile Engineering,Islamic Azad University,South Tehran Branch,Tehran, Iran

'Department of Polymer and Chemical Engineering,Islamic Azad University, South Tehran Branch,Tehran, Iran

A R T I C L E IN F O :

Received 28 Jul 2021

Revised form 7 Oct 2021

Accepted 10 Nov 2021

Available online 30 Dec 2021

Keywords:

Adsorption,

ZSM-5/Fe nanozeolite,

Freundlich,

Langmuir,

UV-Vis Spectrophotometry

\begin{abstract}
A B S T R A C T
The life-threatening nature of high nitrate concentrations in various water resources motivated the present study to investigate the nitrate adsorption by ZSM-5 nanozeolite and the feasibility of increasing nitrate removal efficiency using iron-doped ZSM-5 (ZSM-5/Fe) nanoadsorbent. The optimal adsorption conditions were determined first by modeling the central composite design (CCD) using Design Expert.7 software based on four influential factors of contact time, $\mathrm{pH}$, adsorbent dosage and initial nitrate concentration. Then, the isotherms of nitrate adsorption under optimized conditions were investigated using the degree of fit of experimental data with Langmuir and Freundlich models for mathematical modelling of the nitrate adsorption process. Based on the test design results, the highest nitrate removal efficiency (\%93.1) was determined with UVVis spectrophotometry at the contact time of $150 \mathrm{~min}, \mathrm{pH}$ value of 3 , the adsorbent dosage of $4 \mathrm{~g} \mathrm{~L}^{-1}$ and initial concentration of $40 \mathrm{mg}$ $\mathrm{L}^{-1}$. Analysis of adsorption isotherms also confirmed the greater fit of the experimental data with the Freundlich equation, so that the correction factor of the Freundlich equation was greater than the Langmuir equation, due to the heterogeneous distribution of active sites for adsorption on the ZSM-5/Fe nanosorbent surface. Therefore, it can be concluded that $\mathrm{ZSM}-5 / \mathrm{Fe}$ is a high efficiency nanosorbent for nitrate removal from water resources.
\end{abstract}

\section{Introduction}

Nitrate is known to be one of the most serious threats to human health in the world, which enters the human body through the penetration into groundwater and surface water resources following the excessive use of chemical fertilizers and uncontrolled discharge without nitrification of municipal and industrial wastewater in the environment [1-3]. This ion is

\footnotetext{
*Corresponding Author: Mohsen Zeeb

Email: zeeb.mohsen@gmail.com

https://doi.org/10.24200/amecj.v4.i04.154
}

relatively non-toxic in nature, but its reduction to nitrite by microorganisms can pose serious health risks to humans, including blue baby syndrome, also known as infant methemoglobinemia [4-7]. Accordingly, the EPA has recommended that the maximum permissible concentration of nitrate is $10 \mathrm{mg} \mathrm{L}^{-1}$ in drinking water [8]. Hence, various methods have been previously employed to remove nitrate from aqueous solutions, such as adsorption, ion exchange, reverse osmosis, chemical and biological methods. In recent years, adsorption methods have attracted much attention 
in the removal of mineral ions, including fluoride, nitrate, bromate and perchlorate from water and wastewater. Conventional chemical adsorbents today include those based on carbon, clay, zeolite, chitosan, bilayer compounds (hydroxide/ hydrotalcite), agricultural and industrial wastes, and miscellaneous group [9-19]. Many researchers at present are focusing on zeolites as natural adsorbents of environmental pollutants through ion exchange or adsorption or both due to large specific surface area, unique channel structure, high-temperature hydrothermal stability and high modifiability to enhance adsorption efficiency [20-25]. Kamarehie et al. fabricated a natural nanosorbent using granular activated carbon from grape wood coated with iron nanoparticles to remove nitrate from aqueous solutions. The adsorption was then investigated by the Freundlich isotherm model. Their results showed that more than $99 \%$ of nitrate was removed from the solution with this nanosorbent [26]. Mazarji et al removed nitrate from the aqueous solution using modified granular activated carbon. They modified a commercial granular activated carbon with sodium hydroxide to increase nitrate removal efficiency, followed by examining parameters such as adsorbent dosage, solution $\mathrm{pH}$, contact time and initial nitrate concentration and temperature in the nitrate adsorption process. They concluded that the use of two-step treatment could be a promising method in improving the efficiency of activated carbon to remove nitrate from water [27]. Hafeshjani et al. used sugarcane residues to remove nitrate from aqueous solutions, and investigated the physicochemical properties of the adsorbent such as morphology, element composition, ion exchange capacity and specific surface area. They measured parameters such as $\mathrm{pH}$, adsorbent dosage, contact time, initial nitrate concentration and temperature using different adsorption kinetic models such as Freundlich, Langmuir and others. Their results indicated that the maximum nitrate removal efficiency was achieved at $\mathrm{pH}$ value of 4.64, contact time of 60 minutes, adsorbent dosage of $2 \mathrm{~g} \mathrm{~L}^{-1}$ and the best models were Langmuir isotherm model and Pseudo-second-order kinetic model [28]. Meftah et al modified natural nanozeolite with 3-aminopropyl triethoxysilane and investigated the optimal conditions for nitrate adsorption capacity of modified zeolite in aqueous solutions. Their results revealed that the best nitrate removal capacity $(80.12 \%)$ was obtained at the lowest $\mathrm{pH}$ value of 3 and nitrate concentration of $50 \mathrm{mg} \mathrm{L}^{-1}$ and adsorbent dosage of $4 \mathrm{~g} \mathrm{~L}^{-1}$ [29]. Alimohammadi et al optimized the nitrate removal efficiency using magnetic multi-walled carbon nanotubes by response surface methodology (RSM). They measured two parameters of $\mathrm{pH}$ and $\mathrm{D} / \mathrm{C}$ ratio with quadratic models using RSM, and reported the maximum nitrate removal efficiency (\%97.15) at $\mathrm{pH}=4$ and $\mathrm{D} / \mathrm{C}=40 \mathrm{mg}$ per $\mathrm{mg} \mathrm{L}^{-1}$. It is worth mentioning that they used the Freundlich adsorption isotherm to interpret the adsorption dosage [30]. Azari et al. fabricated a zeolite modified with hydrochloric acid to remove nitrate from aqueous solutions, and investigated the effects of $\mathrm{pH}$, strings speed, contact time, and optimum adsorbent dosage for this nanosorbent under isotherm equations. Their results revealed that the optimum conditions for $\mathrm{pH}$, contact time and adsorbent dosage for maximum nitrate removal with this nanosorbent were 5, $180 \mathrm{~min}$ and $16 \mathrm{~g} \mathrm{~L}^{-1}$, respectively, confirming higher removal efficiency compared to simple unmodified zeolite due to the presence of larger sites [31]. Sepehri et al. presented a natural zeolite-supported zero-valent iron nanoparticles (ze-Nzvi adsorbent) using the sodium borohydride reduction method with the aim of removing nitrate from aqueous solution. Then, they measured the parameters of contact time, adsorbent dosage, initial nitrate concentration, initial $\mathrm{pH}$, the results of which showed that the nitrate removal efficiency was decreased with increasing the initial solution $\mathrm{pH}$ and the adsorbent dosage but elevated with increasing the initial nitrate concentration [32]. Fataei et al investigated the effects of iron and sand nanoparticles on nitrate removal efficiency on a laboratory scale. In this research, they tested the effect of $\mathrm{pH}$, sand and iron particles parameters on nitrate removal efficiency. 
The mixture of iron and sand particles elevated efficiency and specific area. The results showed that the efficiency of iron nanoparticles was $65 \%$ in the first $20 \mathrm{~min}$ and $45 \%$ in the next times when the $\mathrm{pH}$ of the reactions increased. Therefore, the results confirmed that the initial solution $\mathrm{pH}$ was important in the maximum nitrate removal efficiency [33]. Bhatnagar et al. introduced nanoalumina to remove nitrate from aqueous solution. In their study, they examined the parameters of contact time, $\mathrm{pH}$, nitrate concentration with a pseudo-secondorder kinetic model. The highest nitrate removal efficiency was achieved at a concentration of $4 \mathrm{mg}$ $\mathrm{g}^{-1}$, a temperature of $23-27^{\circ} \mathrm{C}$ and a $\mathrm{pH}$ value of 4.4. Langmuir isotherm model was performed to analyze the nitrate adsorption. The results of this study verified the nano-alumina as a useful and effective adsorbent for the nitrate removal from aqueous solutions [34].

Given that metals such as Al, Sn, Zn, Fe and Ni are effective agents for remediation of contaminated groundwater, hence the present study tested iron metal due to its availability, inexpensiveness, nontoxicity, high efficiency and rapid reaction in the decomposition of contaminants to functionalize ZSM-5 nanozeolite with the aim of determining the optimal conditions and effective factors in nitrate removal, including $\mathrm{pH}$, contact time and adsorbent dosage using RSM as well as evaluating the adsorption isotherms.

\section{Experimental}

\subsection{Material}

The ZSM-5 nanocatalyst powder (from the Zeolites family) was purchased from Sigma Aldrich with a crystal size of $0.5 \mu \mathrm{m}$ and a pore size of $5.5 \mathrm{~A}^{0}$. Ferric chloride $\left(\mathrm{FeCl}_{3}\right)$, sodium hydrocside $(\mathrm{NaOH})$, Potassium nitrate $\left(\mathrm{KNO}_{3}\right)$, Hydrocloric acid $(\mathrm{HCl})$ and $\% 98$ sulfuric acid $\left(\mathrm{H}_{2} \mathrm{SO}_{4}\right)$ were also obtained from Merck Germany.

\subsection{Materials characterization}

X-ray diffraction (XRD, STADI-P, the USA) and energy-dispersive X-ray spectroscopy (EDX, MIRA III SAMX, Czech Republic) was used to investigate ferrous $(\mathrm{Fe})$ metal in the nanocatalyst structure functionalized with these metal. BrunauerEmmett-Teller (BET) surface area analysis (Belsorb apparatus, Japan) was used to determine the SSA of nanocatalyst particles. The concentration of nitrate was determined by spectrophotometer UV-Vis (Hach model Dr2800) was used.

\subsection{Preparation of ZSM-5/Fe Nanozeolite}

To Preparation the functionalized ZSM-5 nanocatalyst, first $2.5 \mathrm{~g}$ of ZSM-5 nanozeolite powder was placed in the furnace at a temperature of $500^{\circ} \mathrm{C}$ for 4 hours and calcined. Then, $0.5 \mathrm{~g}$ of ferric chloride $\left(\mathrm{FeCl}_{3}\right)$ powder was dissolved in distilled water twice for one hour, added to the calcined ZSM-5 nanozeolite powder and mixed for another 30 minutes, and filtered with a filter paper. The resulting powder was rinsed three times with distilled water and placed in an oven at a temperature of $80^{\circ} \mathrm{C}$ for 2 hours. Next, the powder was separated from the filter paper and re-calcined at a temperature of $500^{\circ} \mathrm{C}$ for 4 hours. The method of preparation above nanocatalyst is schematically illustrated in Fig.1.

\subsection{Preparation of solutions}

To prepare a standard concentrated potassium nitrate solution, $7 \mathrm{~g}$ of anhydrous $\mathrm{KNO}_{3}$ was dried at $100^{\circ} \mathrm{C}$ for an hour. After cooling, $1.805 \mathrm{~g}$ of $\mathrm{KNO}_{3}$ was dissolved in a volumetric flask and diluted to $250 \mathrm{~mL}$, thus preparing a standard solution of 1000 $\mathrm{mg} \mathrm{L}^{-1}$ or $1.0 \mathrm{mg} \mathrm{mL}^{-1}$. HCL and $\mathrm{NaOH}$ solutions were prepared to set the $\mathrm{pH}$ values. Then, nitrate solutions with concentrations of 20,40,60, 80, 100 and $120 \mathrm{mg}$ per liter were prepared from the standard solution of potassium nitrate $1000 \mathrm{mg} \mathrm{L}^{-1}$.

\subsection{Procedure}

In this research, the experimental design table was first provided using the effective variables of $\mathrm{pH}$, contact time and stirring speed in the intervals defined to RSM and the central composite design (CCD) by Design Expert.7 software. Then, the value of each parameter was provided according to the experimental design table and finally the 


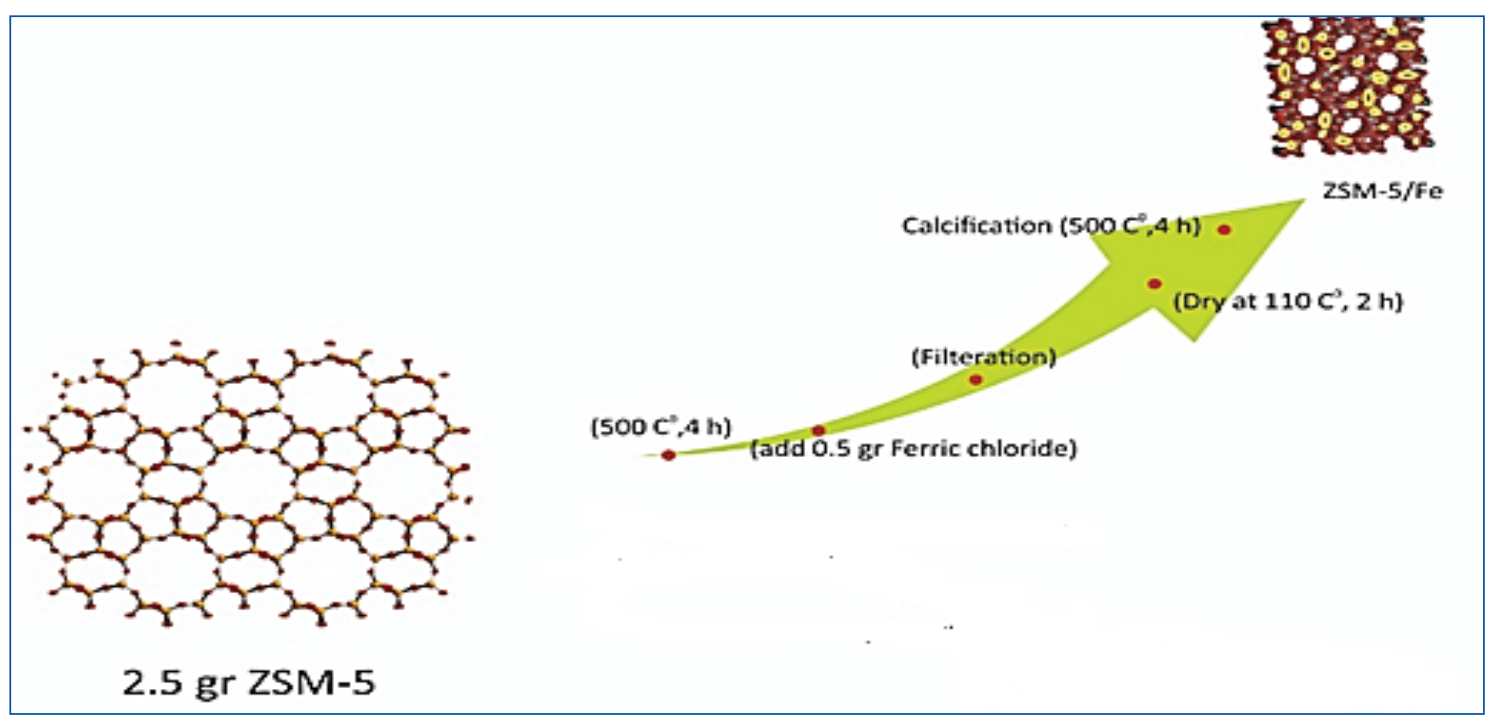

Fig.1. Schematic of ZSM-5/Fe nanosorbent fabrication method

absorbance values or nitrate concentrations were measured by UV-Vis spectrophotometry. The results were analyzed by experimental design software, and the optimal values of $\mathrm{pH}$, contact time and stirring speed were determined. In the next step, the isotherms of nitrate adsorption under optimized conditions were investigated using the degree of fit of experimental data with Langmuir and Freundlich models for mathematical modeling of the nitrate adsorption process.

\subsection{Langmuir adsorption model}

The mathematical model of this isotherm is shown in Equation 1and 2 .

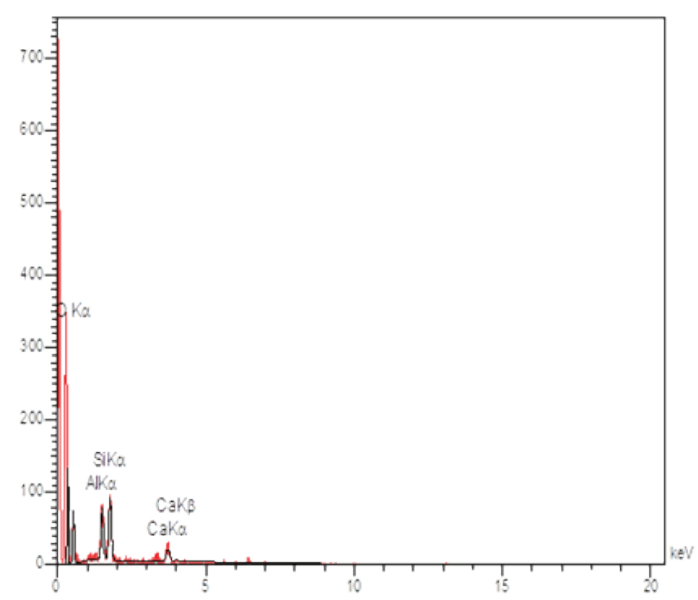

Fig. 2. Energy-dispersive X-ray spectroscopy (EDX) analysis of the ZSM-5 and ZSM-5/Fe
$\mathrm{q}_{\mathrm{e}}=\mathrm{q}_{\max } \mathrm{bc} / 1+\mathrm{bC} \mathrm{e}_{\mathrm{e}}$
(Eq. 1)
$1 / \mathrm{q}_{\mathrm{e}=} 1 / \mathrm{q}_{\max } \mathrm{bc}+1 / \mathrm{q}_{\max }$
(Eq. 2)

Where, $\mathrm{q}_{\max }$ and $\mathrm{b}$ stand for experimental constants, $\mathrm{q}_{\mathrm{e}}$ for the amount of substance absorbed per unit mass of adsorbent $\left(\mathrm{mg} \mathrm{g}^{-1}\right)$ and $\mathrm{C}_{\mathrm{e}}$ for the equilibrium adsorbate concentration in solution $\left(\mathrm{mg} \mathrm{L}^{-1}\right)$.

\subsection{Freundlich adsorption model}

Equation 3 shows the mathematical model of the Freundlich isotherm. Where, qe and Ce are similar to the Langmuir isotherm, and $\mathrm{n}$ and $\mathrm{K}$ stand for Freundlich constants. The linear equation of the Freundlich isotherm is as equation 4.

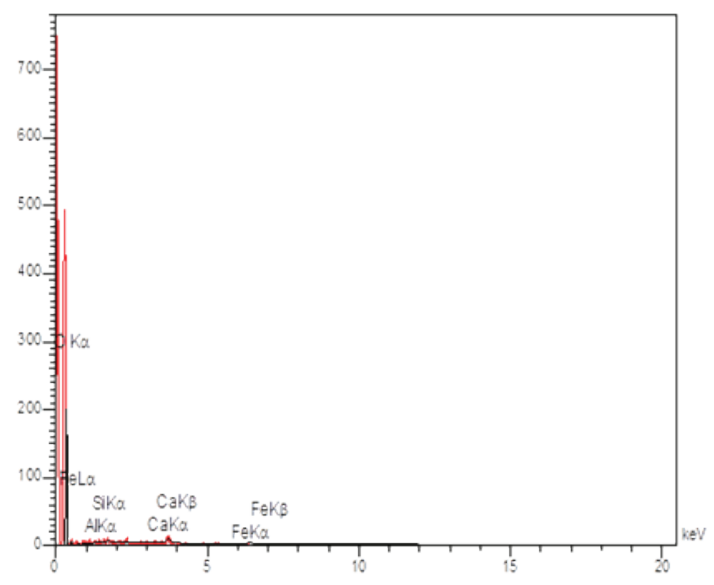




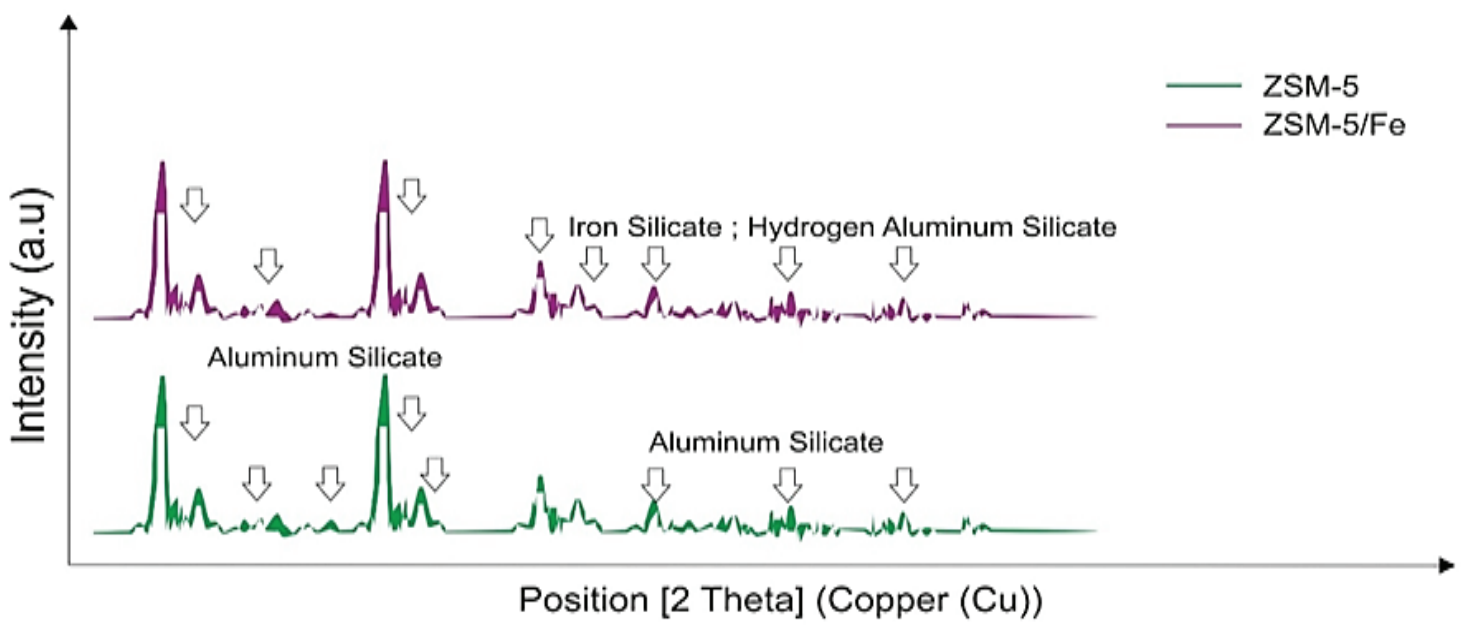

Fig. 3. Investigation of nickel doping by X-ray diffraction (XRD) analysis

$\mathrm{q}_{\mathrm{e}}=\mathrm{K}_{\mathrm{f}} \mathrm{C}_{\mathrm{e}}^{1 / \mathrm{n}}$

$\log \mathrm{q}_{\mathrm{e}}=\log \mathrm{K}+1 / \mathrm{n} \log \mathrm{C}_{\mathrm{e}}$

\section{Results and Discussion}

\subsection{Investigation of electrode surface} modification by EDX and XRD analysis

According to Figure 2 the presence of iron particles in the nanosorbent structure is quite evident. The
XRD spectrum for the ZSM-5/Fe nanozeolite confirms the presence of iron particles doped with silicate particles(Fig.3).

\subsection{BET characterization}

By comparing the BET parameter (Fig.4 and Table 1 ), in each of the four BET analysis curves of the nanozeolite, the highest SSA was related to the catalyst functionalized with Fe metal (ZSM-5/Fe, which was determined to be $\left.408.41 \mathrm{~m}^{2} \mathrm{~g}^{-1}\right)$.
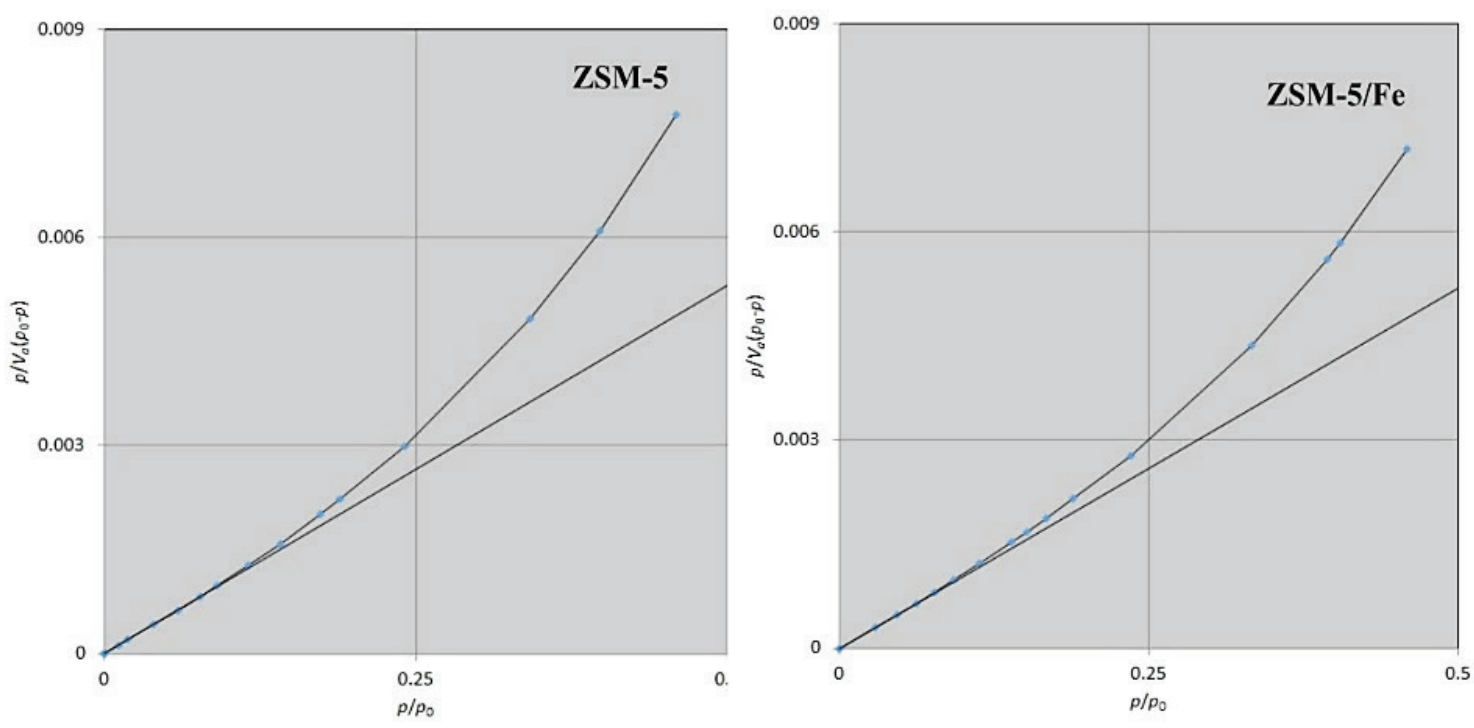

Fig.4. BET curves of prepared nanosorbent 
Table 1. The specific surface area of prepared nanozeolite

\begin{tabular}{cccc}
\hline Row & Nanocatalysts & BET & Unit \\
\hline 1 & ZSM-5 & 374.66 & $\mathrm{~m}^{2} \mathrm{~g}^{-1}$ \\
2 & ZSM-5/Fe & 408.41 & $\mathrm{~m}^{2} \mathrm{~g}^{-1}$ \\
\hline
\end{tabular}

\subsection{Optimization and experimental design}

In this research, the experimental design using RSM in combination with CCD method was performed to investigate the effects of influential variables of $\mathrm{pH}$ (in the range of 2-8) (A), contact time (30-180 minutes) (B) and adsorbent dosage (1-5 $\left.\mathrm{g} \mathrm{L}^{-1}\right)(\mathrm{C})$ on nitrate removal efficiency. Due to the extensive use of research on (A), (B) and (C) parameters for the nitrate removal process, these parameters were selected as effective factors in optimizing nitrate removal [35-40] [41s,42s, This referenceshowed in supporting nformation page, SIP]. The RSM method is a mathematical and statistical method used for the analysis and empirical modeling of problems where a given answer is influenced by several variables and the RSM can be calculated to determine the optimal conditions. One advantage of this method is to reduce the number of empirical tests performed to obtain statistically valid results. In addition, the RSM method can also analyze the interactions between variables. Therefore, the use of this method in optimization can report more comprehensive and accurate data by performing the least number of experiments [43s-44s, SIP]. Table 2 shows the range of independent variables and design levels of the experiments examined in this study. The results of the complete design of the test and the exact responses of the tests listed in Table 3. According to the results of the data analysis in Table 4, a quadratic function model can fit well to the empirical results. The fit of this model was evaluated by Analysis of Variance (ANOVA), normal probability plot and residual analysis. The quadratic function for nitrate removal efficiency is expressed as follows:

\%Removal Nitrate $=51.29-(11.26 \times \mathrm{A})+(4.76 \times \mathrm{B})-(3.64$

$\times \mathrm{C})+(11.90 \times \mathrm{D})+(5.41 \times \mathrm{A} \times \mathrm{B})+(3.69 \times \mathrm{A} \times \mathrm{C})-(0.062 \times \mathrm{A}$ $\times \mathrm{D})+(3.16 \times \mathrm{B} \times \mathrm{C})+5.76 \times \mathrm{B} \times \mathrm{D})-(2.77 \times \mathrm{C} \times \mathrm{D})+(0.52 \times$ $\left.\mathrm{A}^{2}\right)+\left(0.89 \times \mathrm{B}^{2}\right)+\left(3.23 \times \mathrm{C}^{2}\right)-\left(1.75 \times \mathrm{D}^{2}\right)$

In the Table 4, the ANOVA analysis showed the importance of each parameter in response to nitrate removal by $\mathrm{P}$ and $\mathrm{F}$ values. The smaller the $\mathrm{P}$ value, the higher its impact factor and its contribution to the response variable. The $\mathrm{P}$ values less than 0.05 indicate that the model expressions are significant. The $\mathrm{P}$ values more than 0.1 indicate that the model terms are insignificant. Accordingly, the seven terms of (AC), (BD), and $\left(\mathrm{C}^{2}\right)$ are significant parameters of the model and have the greatest effect on nitrate removal efficiency. The $\mathrm{P}$ values of the other terms were greater than 0.05 , which means that their effect on the response model was not statistically significant.

Figure 5 shows the residual curve in terms of the

Table 2. Factors and levels for CCD study.

\begin{tabular}{cccc}
\hline Level & $\mathrm{pH}$ & Tempture & Time \\
\hline$\alpha-$ & 22.4874 & -4.31981 & -13.7046 \\
-1 & 3 & 5 & 1 \\
+1 & 8 & 50 & 72 \\
$\alpha+$ & 472.487 & 59.3198 & 86.7046 \\
\hline
\end{tabular}


Table 3. Experimental range and values of different variables studied.

\begin{tabular}{llllcccc}
\hline Std & Run & Block & pH & Time & nitrate absorbent & \%Removal \\
& & & & $(\mathbf{m i n})$ & $\left(\mathbf{m g L}^{-1}\right)$ & $\left(\mathbf{g r L}^{-1}\right)$ & Nitrate(mgL $\left.\mathbf{m}^{-1}\right)$ \\
\hline 5 & 1 & Block 1 & 7 & 60 & 40 & 4 & 48.76 \\
7 & 2 & Block 1 & 3 & 150 & 100 & 4 & 81.23 \\
11 & 3 & Block 1 & 5 & 105 & 70 & 3 & 53.22 \\
8 & 4 & Block 1 & 3 & 60 & 40 & 2 & 71.66 \\
12 & 5 & Block 1 & 5 & 105 & 70 & 3 & 54.6 \\
1 & 6 & Block 1 & 7 & 150 & 100 & 2 & 47.13 \\
10 & 7 & Block 1 & 5 & 105 & 70 & 3 & 50.62 \\
3 & 8 & Block 1 & 7 & 60 & 100 & 4 & 38.62 \\
9 & 9 & Block 1 & 5 & 105 & 70 & 3 & 55.91 \\
6 & 10 & Block 1 & 3 & 60 & 100 & 2 & 57.84 \\
2 & 11 & Block 1 & 7 & 150 & 40 & 2 & 33.56 \\
4 & 12 & Block 1 & 3 & 150 & 40 & 4 & 93.51 \\
14 & 13 & Block 2 & 8 & 105 & 70 & 3 & 28.64 \\
17 & 14 & Block 2 & 5 & 105 & 20 & 3 & 63.28 \\
20 & 15 & Block 2 & 5 & 105 & 70 & 5 & 61.17 \\
22 & 16 & Block 2 & 5 & 105 & 70 & 3 & 53.76 \\
21 & 17 & Block 2 & 5 & 105 & 70 & 3 & 50.44 \\
15 & 18 & Block 2 & 5 & 30 & 70 & 3 & 40.62 \\
18 & 19 & Block 2 & 5 & 105 & 120 & 3 & 47.19 \\
13 & 20 & Block 2 & 2 & 105 & 70 & 3 & 66.51 \\
19 & 21 & Block 2 & 5 & 105 & 70 & 1 & 21.13 \\
16 & 22 & Block 2 & 5 & 180 & 70 & 3 & 56.62 \\
\hline & & & & & & &
\end{tabular}

Table 4. Experimental design and actual results of nitrate removal efficiency.

\begin{tabular}{lrrrrr}
\hline Source & $\begin{array}{c}\text { Sum of } \\
\text { Squares }\end{array}$ & df & $\begin{array}{c}\text { Mean } \\
\text { Square }\end{array}$ & $\begin{array}{c}\text { F } \\
\text { Value }\end{array}$ & $\begin{array}{c}\text { p-value } \\
\text { Prob }>\text { F }\end{array}$ \\
\hline Block & 374.47 & 1 & 374.47 & ----- & ----- \\
Model & 5147.23 & 14 & 367.66 & 20.32 & 0.0007 \\
significant & & & & & \\
A-pH & 717.07 & 1 & 717.07 & 39.64 & 0.0007 \\
B-Time & 128.00 & 1 & 128.00 & 7.08 & 0.0375 \\
C-gr nitrate & 181.09 & 1 & 181.09 & 10.01 & 0.0195 \\
D-gr absorbent & 801.60 & 1 & 801.60 & 44.31 & 0.0006 \\
AB & 97.08 & 1 & 97.08 & 5.37 & 0.0597 \\
AC & 109.00 & 1 & 109.00 & 6.03 & 0.0495 \\
AD & 0.013 & 1 & 0.013 & $7.024 \mathrm{E}-004$ & 0.9797 \\
BC & 79.70 & 1 & 79.70 & 4.41 & 0.0806 \\
BD & 110.03 & 1 & 110.03 & 6.08 & 0.0487 \\
CD & 61.44 & 1 & 61.44 & 3.40 & 0.1149 \\
A 2 & 4.23 & 1 & 4.23 & 0.23 & 0.6457 \\
B 2 & 12.30 & 1 & 12.30 & 0.68 & 0.4411 \\
C & 160.98 & 1 & 160.98 & 8.90 & 0.0245 \\
D & 47.05 & 1 & 47.05 & 2.60 & 0.1579 \\
Residual & 108.53 & 6 & 18.09 & & \\
Lack of Fit & 87.66 & 2 & 43.83 & 8.40 & 0.0370 \\
significant & & & & & \\
Pure Error & 20.87 & 4 & 5.22 & & \\
Cor Total & 5630.23 & 21 & & & \\
\hline
\end{tabular}


predicted response for response of nitrate removal efficiency. This Figure shows that all empirical data are uniformly distributed around the mean response variable. This indicates that the proposed model is sufficient and there has been no deviation from the hypotheses made. As can be seen in Table 5, the difference between the adjusted $\mathrm{R}^{2}$ and the predicted $\mathrm{R}^{2}$ is less than 0.2 and the precision of the model is 19.613 (which is greater than 4), indicating the used model is accurate.

Figure 6 shows a comparison between the actual

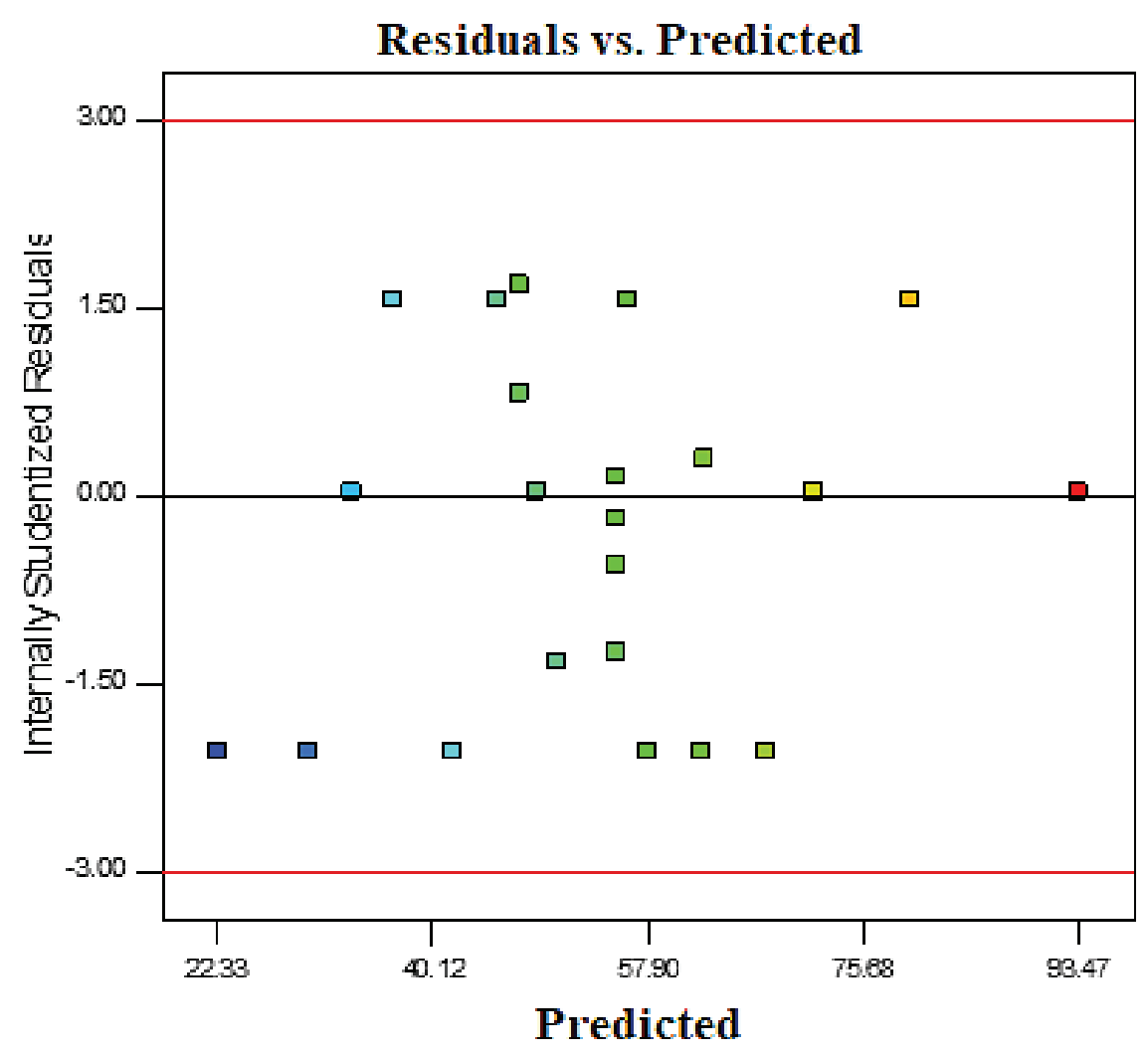

Fig.5.The residual value curve in terms of the predicted response

Table 5. Model equation statistical parameters for ANOVA model for nitrate removal efficiency.

\begin{tabular}{lc}
\hline Type of variables & Results \\
\hline Std. Dev. & 4.25 \\
R-Squared & 0.9793 \\
Mean & 53.46 \\
Adj R-Square & 0.9312 \\
C.V. \% & 7.96 \\
Pred R-Squared & -4.0544 \\
PRESS & 26564.71 \\
Adeq Precision & 19.613 \\
\hline
\end{tabular}


response values obtained from the empirical results and the predicted response values obtained from the quadratic function model equation. It is observed that the model describes the empirical results and data fairly accurately, meaning that it has been successful in comparing the correlations between the three variables. In addition, there is a sufficient correlation with the linear regression coinciding with the $\mathrm{R}$ value of about 0.9793 . In addition, Figure 7 shows the three-dimensional interaction curves of contact time, $\mathrm{pH}$, adsorbent dosage and initial nitrate concentration for nitrate removal efficiency. The highest nitrate removal efficiency was reported at the contact time of 150 min, $\mathrm{pH}$ value of 3 , adsorbent dosage of $4 \mathrm{~g} \mathrm{~L}^{-1}$ and initial concentration of $40 \mathrm{mg} \mathrm{L}^{-1}$. Analysis of the diagrams in Figure 7 revealed higher nitrate removal efficiency at lower $\mathrm{pH}$ values and longer contact times.

\subsection{Absorption isotherms and measurements}

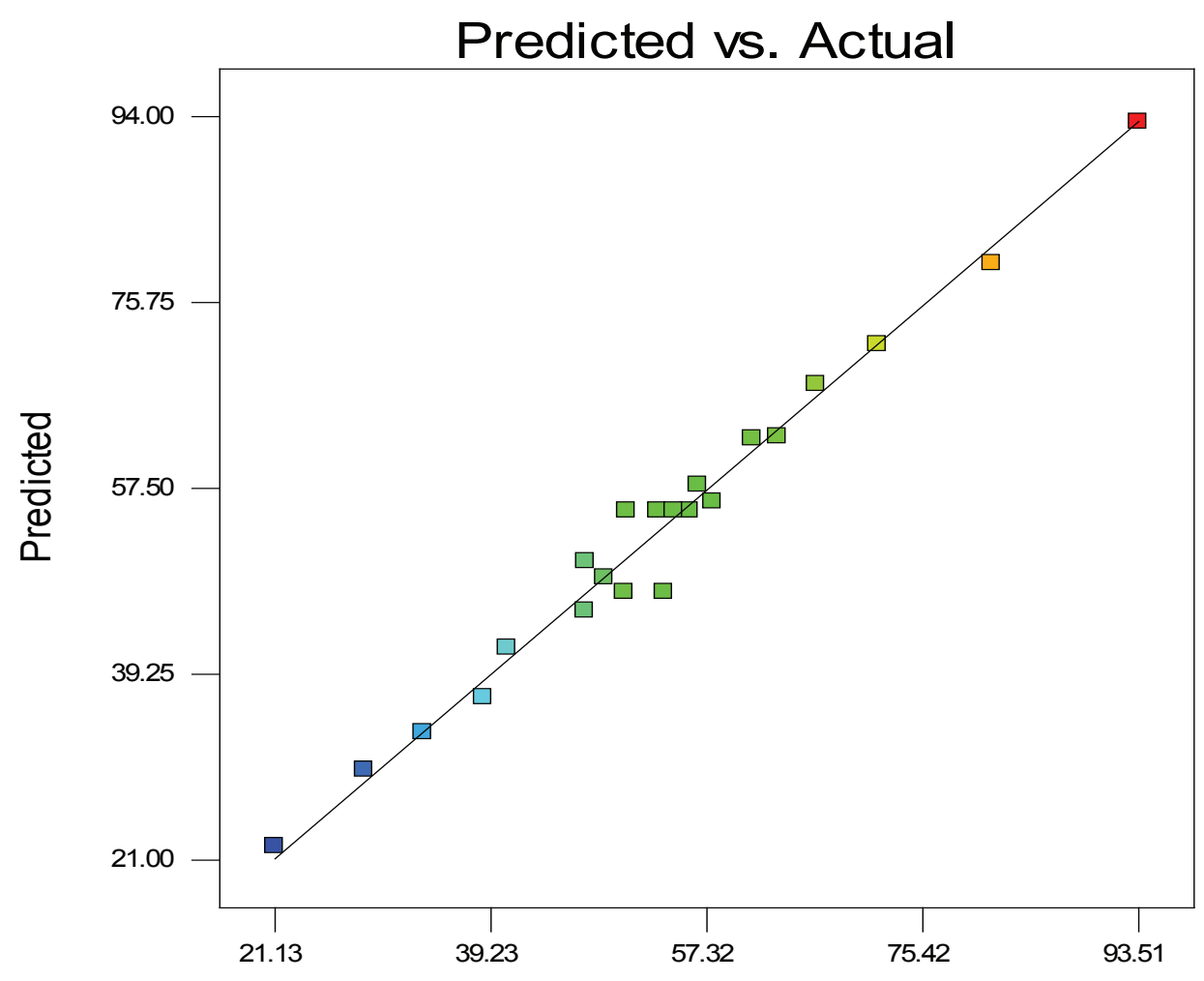

Actual

Fig. 6. Comparison between predicted and actual empirical values of nitrate removal efficiency 


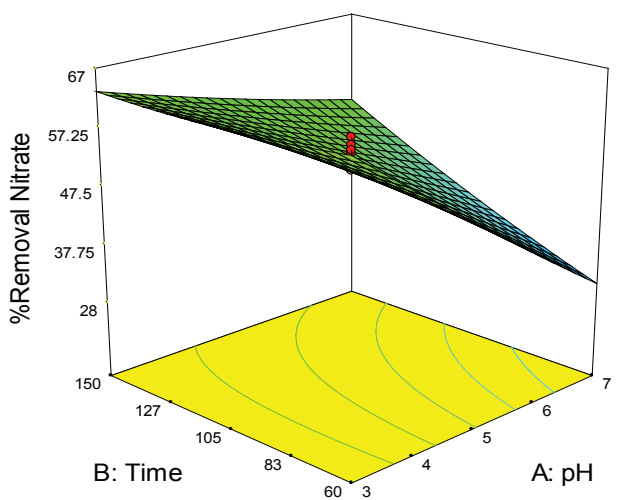

A

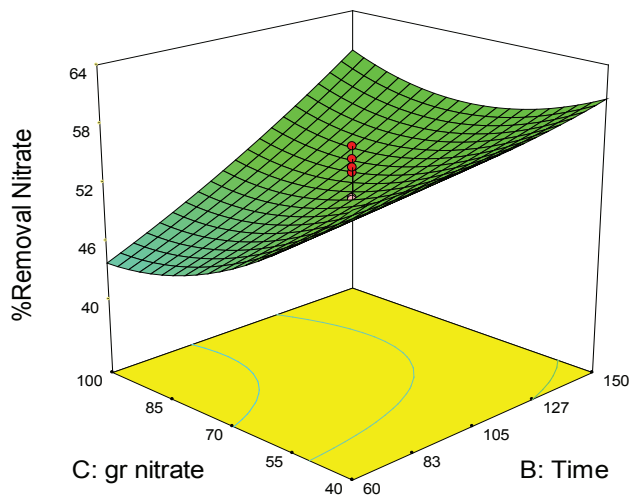

B

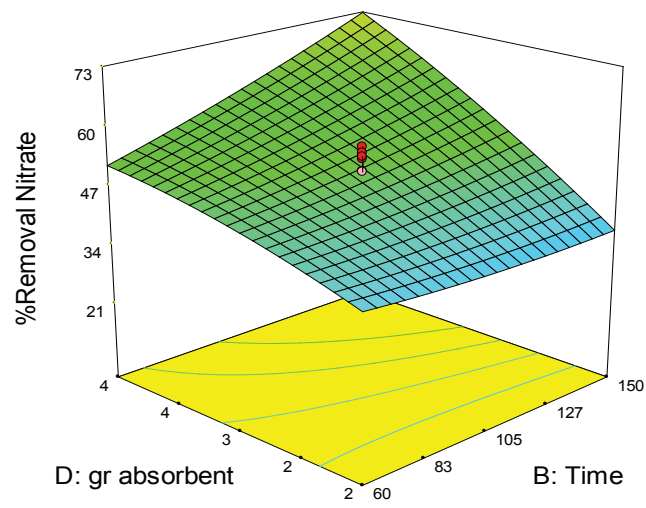

C

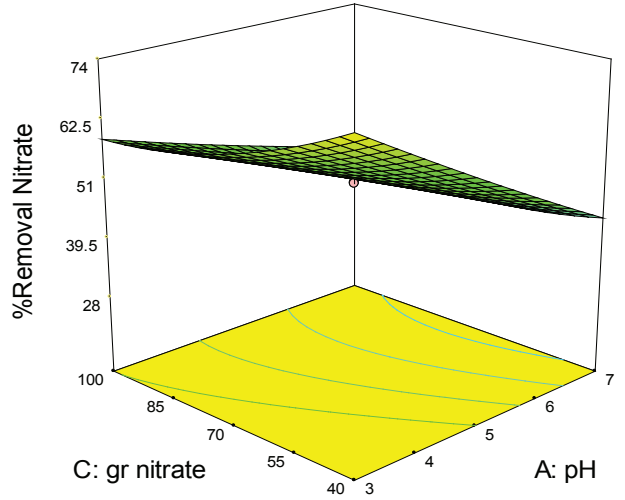

$\mathrm{D}$

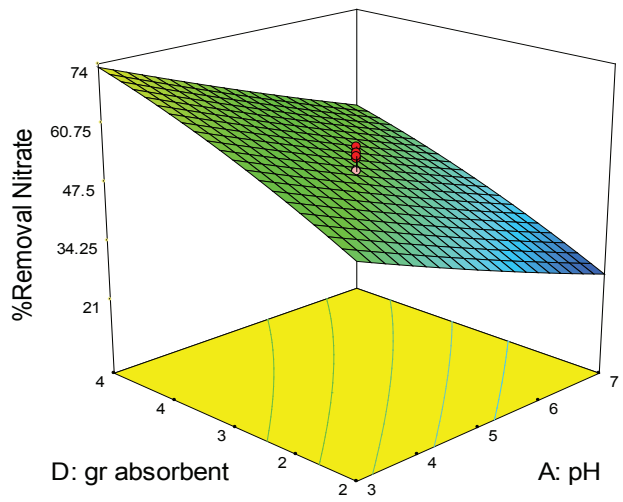

E

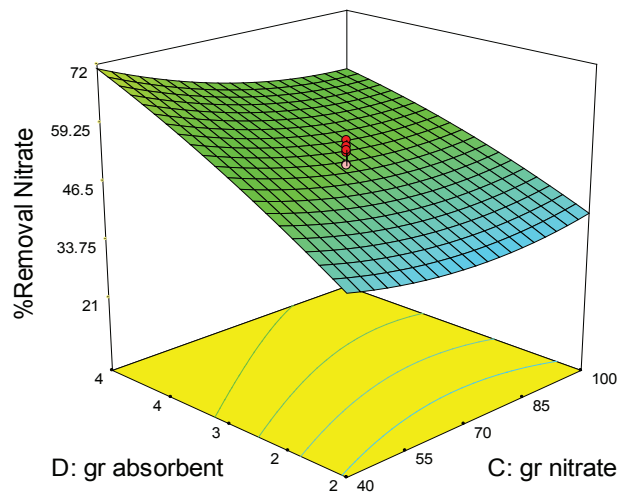

F

Fig.7. 3D response surface method curves of nitrate removal efficiency 
The nitrate adsorption efficiency was measured by dissolving $4 \mathrm{~g}$ of adsorbent in $250 \mathrm{~mL}$ of nitrate solution at the initial concentrations of $20-120 \mathrm{mg}$ at the contact time of $150 \mathrm{~min}$ at laboratory temperature and the stirring speed of $50 \mathrm{rpm}$. Finally, the equilibrium concentration of nitrate in solutions was determined by the UV-Vis spectrophotometry at 220 and $275 \mathrm{~nm}$. The equilibrium nitrate adsorption capacity was calculated by the equation 5 . Where, $\mathrm{q}_{\mathrm{e}}$ is the equilibrium adsorption capacity $\left(\mathrm{mg} \mathrm{g}^{-1}\right), \mathrm{C}_{\mathrm{e}}$ is the equilibrium concentration of nitrate ion $(\mathrm{mg}$ $\left.\mathrm{L}^{-1}\right), \mathrm{V}$ is the solution volume (L) and $\mathrm{M}$ is the adsorbent dosage ( $\mathrm{g}$ ).

$\mathrm{q}_{\mathrm{e}}=\left(\mathrm{C}_{0}-\mathrm{C}_{\mathrm{e}}\right) \mathrm{V} / \mathrm{M}$

\subsubsection{Nitrate adsorption isotherm}

Nitrate adsorption on ZSM-5/Fe adsorbent was determined at laboratory temperature in terms of equilibrium concentration, as shown by the corresponding adsorption diagrams in Figures 8 and 9. Langmuir and Freundlich adsorption models were employed to evaluate the adsorption isotherm data. These models describe the relationship between the amount of ion adsorption desired on the adsorbent surface and its equilibrium concentration in the liquid phase. The Langmuir and Freundlich isotherms indicate mono-layer and multi-layer adsorption on surfaces, respectively. The Langmuir isotherm reveals active sites with a limited number, while the Freundlich equation represents heterogeneous surfaces $[45 \mathrm{~s}, \mathrm{SIP}]$. By procedure, first the experimental data were fitted with Langmuir and Freundlich equations and then the constant parameters of the isotherm equations were calculated. The Langmuir and Freundlich models are explained by Equations 6 and 7, respectively.

$\mathrm{q}_{\mathrm{e}}=\left(\mathrm{qm} \mathrm{KLC}_{\mathrm{e}}\right) /\left(1+\mathrm{KLC}_{\mathrm{e}}\right)$

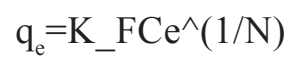

Where, $\mathrm{q}_{\mathrm{m}}$ stands for the maximum adsorption capacity $\left(m g \mathrm{~g}^{-1}\right), \quad \mathrm{C}_{\mathrm{e}}$ for the equilibrium concentration of nitrate ion $\left(\mathrm{mg} \mathrm{L}^{-1}\right), \mathrm{KL}$ for the constant of Langmuir isotherm $\left(\mathrm{L} \mathrm{mg}^{-1}\right)$, and KF $\left(\mathrm{mg} \mathrm{g}^{-1}\right)$ and $\mathrm{N}$ are the constants of Freundlich isotherm.

According to the results, the correction factor for the Freundlich equation is larger than that for the Langmuir equation, indicating experimental data well-described with the Freundlich equation. This fact is probably due to the heterogeneous distribution of adsorption active sites on the adsorbent surface, because the Freundlich model assumes the adsorbent surface heterogeneity. The values of parameter $\mathrm{N}$ in Freundlich model are less than unit, which indicates an increase in bond energy with surface density and shows the optimal nitrate absorption conditions $[46 \mathrm{~s}-47 \mathrm{~s}$, SIP]. The effective parameters of isotherm models obtained from regression analysis of experimental data are reported in Table 6.

\section{Conclusions}

Table 6. Parameters of Langmuir and Freundlich adsorption isotherms for nitrate adsorption on ZSM-5/Fe adsorbent

\begin{tabular}{cccccc}
\hline $\mathrm{R} 2$ & $\mathrm{KL}\left(\mathrm{L} \mathrm{mg}^{-1}\right)$ & $\mathrm{qm}(\mathrm{mg} \mathrm{g}-1)$ & $\mathrm{R} 2$ & $\mathrm{~N}$ & $\mathrm{KF}\left(\mathrm{mg} \mathrm{g}^{-1}\right)$ \\
\hline 0.9881 & 0.290 & 8.072 & 0.9959 & 0.642 & 1.83 \\
\hline
\end{tabular}




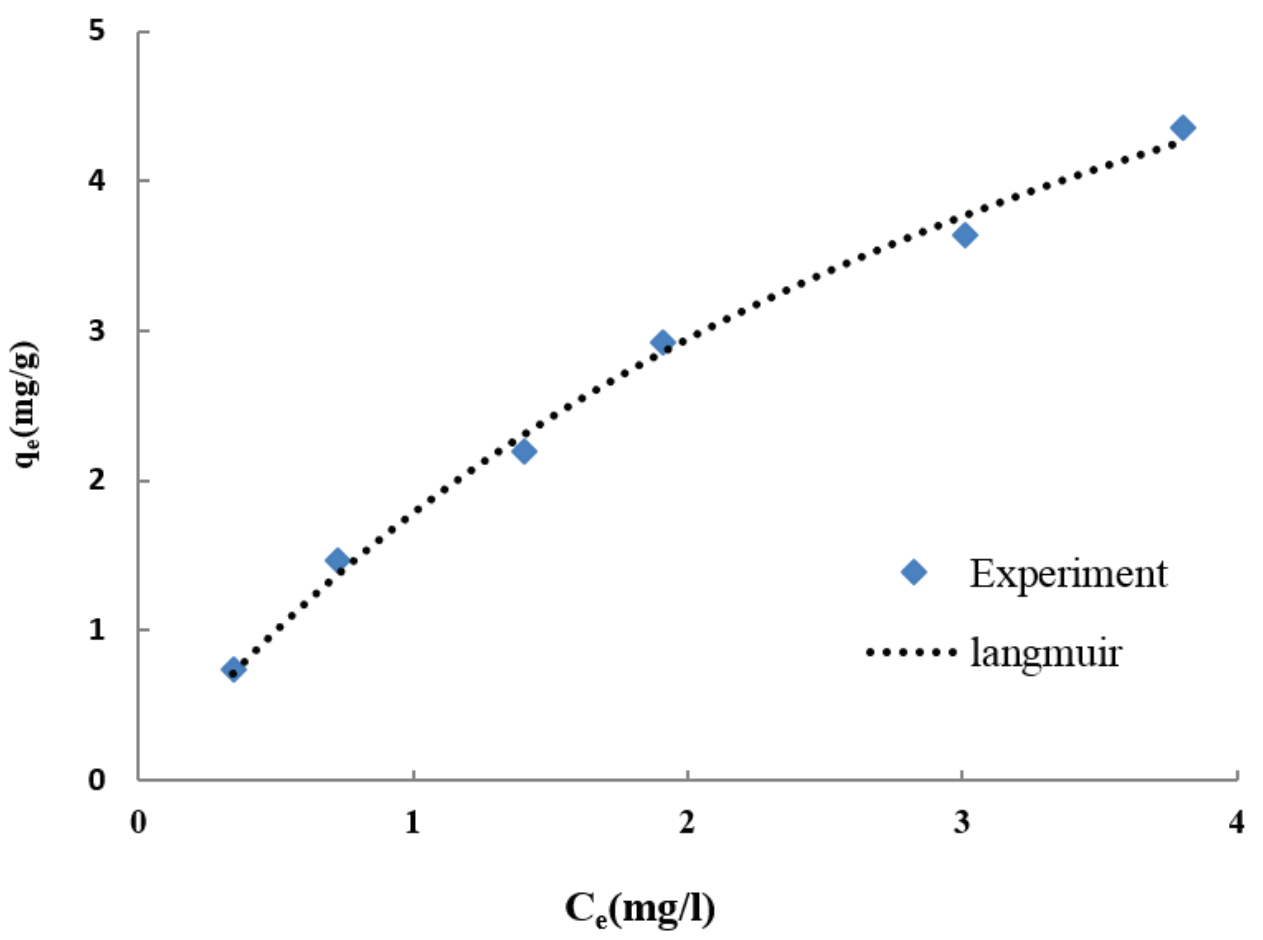

Fig. 8. Langmuir adsorption isotherm for nitrate adsorption on ZSM-5/Fe adsorbent

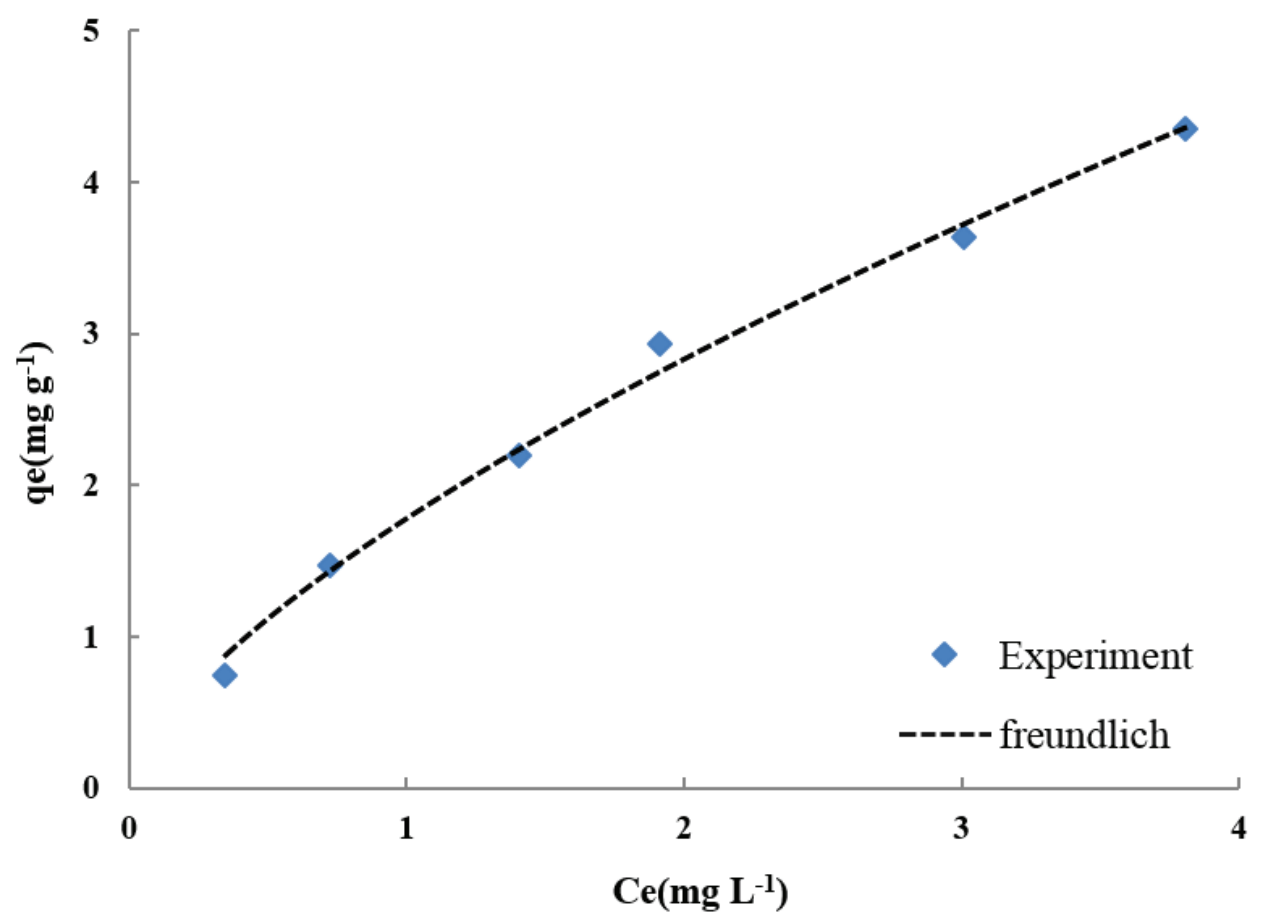

Fig. 9. Freundlich adsorption isotherm for nitrate adsorption on ZSM-5/Fe adsorbent 
According to the results of the experimental design table, the $\mathrm{pH}$ value, contact time and initial nitrate concentration optimized for maximum nitrate removal (\%93.51) were reported as 3, 150 minutes and $40 \mathrm{mg} \mathrm{L}^{-1}$, respectively. In the results of the adsorption isotherms, the correction factor for the Freundlich equation is larger than that for the Langmuir equation, which shows that the experimental data are well described by the Freundlich equation, probably due to the heterogeneous distribution of active adsorption sites on the adsorbent surface because the Freundlich model assumes the adsorbent surface heterogeneity. The values of parameter $\mathrm{N}$ of the Freundlich model are less than unit, indicating the increase of bond energy with surface density and also the optimal conditions of nitrate adsorption. Therefore, it can be concluded that $\mathrm{ZSM}-5 / \mathrm{Fe}$ is a high efficiency nanosorbent for nitrate removal from aqueous solutions. The nitrate concentration in water samples was determined by UV-Vis spectrophotometry

\section{Acknowledgments}

The authors would like to thank and appreciate. Hamid Reza Sardari, Personnel of Chemistry Laboratory at Islamic Azad University, South Tehran Branch, for providing laboratory facilities and equipment.

\section{References}

[1] D.W. Cho, C.M. Chon, B.H. Jeon, Y. Kim, M.A. Khan, H. Song, The role of clay minerals in the reduction of nitrate in groundwater by zero-valent iron, Chemosphere, 81 (2010) 611-616. https:// doi.org/j.chemosphere.2010.08.005

[2] P. Mishra, R. Patel, Use of agricultural waste for the removal of nitrate-nitrogen from aqueous medium, J.Environ. Manage., 90 (2009) 519-22. https://doi.org/10.1016/j.jenvman.2007.12.003

[3] M. Nikaeen, S. Naseri, Evalution of metallic iron $\left(\mathrm{Fe}^{0}\right)$ application to remediate nitrate contaminated water, Water Wastewater, 17 (2007) 15-21. http://www.wwjournal.ir/ article_2222.html?lang=en

[4] S. Shadkam, F. Ludwig, P. van Oel, C. Kirmit,
P. Kabat, Impacts of climate change and water resources development on the declining inflow into Iran's Urmia Lake, J. Great Lakes Res., 42 (2016) 942-952. https://doi.org/10.1016/j. jglr.2016.07.033.

[5] Eslami A, Ghadimi M. Study of five years nitrite and nitrate content trends of Zanjan groundwater resources using GIS from 2006 to 2010, J. Health Field, 1 (2013) 30-6. http://journals.sbmu.ac.ir/jhf

[6] R. Fouladi Fard, M. J. M. Abadi, M. R. Hosseini, Survey the nitrate concentration in drinking water distribution systems of Kashan county, Iran, J. Saf. Environ. Health Res., 1 (2016) 36-39. http:// doi.org/ 10.22053/jsehr.2016.33387

[7] M. Dehghani, E. Haidari, S. Shahsavani, N. Shamsedini, Removal of nitrate in the aqueous phase using granular ferric hydroxide, Jundishapur J. Health Sci., 7(2015) e26419. http://doi.org/ 10.5812/jjhs.7(2)2015.26419

[8] J. Rodríguez-Maroto, F. García-Herruzo, A. García-Rubio, C. Gómez-Lahoz, C.VeredaAlonso, Kinetics of the chemical reduction of nitrate by zero-valent iron, Chemosphere, 74 (2009) 804-809. http://doi.org/10.1016/ jchemosphere.2008.10.020

[9] I.F. Cheng, R. Muftikian, Q. Fernando, N. Korte, Reduction of nitrate to ammonia by zero valent iron, Chemosphere, 35 (1997) 2689-2695. http:// doi.org/10.1016/S0045-6535(97)00275-0

[10] Y.H. Huang, T.C. Zhang, Effects of low pH on nitrate reduction by iron powder, Water Res., 38 (2004) 2631-2642. https://doi.org/10.1016/j. watres.2004.03.015

[11] Y.M. Chen, C.W. Li, S.S. Chen, Fluidized zero valent iron bed reactor for nitrate removal, Chemosphere, 59 (2005) 753-759. http://doi. org/10.1016/chemosphere.2004.11.020

[12] Y.H. Liou, S.L. Lo, C.J. Lin, C.Y. Hu, W.H. Kuan, S.C. Weng, Methods for accelerating nitrate reduction using zerovalent iron at nearneutral $\mathrm{pH}$ : effects of $\mathrm{H}_{2}$-reducing pretreatment and copper deposition, Environ. Sci. Technol., 39 (2005) 9643-9648. http://doi.org/10.1021/ es048038phttps://doi.org/

[13] S.C. Ahn, S.Y. Oh, D.K. Cha, Enhanced 
reduction of nitrate by zero-valent iron at elevated temperatures, J. Hazard. Mater., 156 (2008) 17-22. http://doi.org/10.1016/j. jhazmat.2007.11.04

[14] M. Dore, Ph. Simon, A. Deguin, J. Victot, Removal of nitrate in drinking water by ion exchange-impact on the chemical quality of treated water, Water Res., 20 (1986) 221-232. http://dx.doi.org/10.1016/00431354(86)90012-6

[15] S. Samatya, N. Kabay, U. Yuksel, M. Arda, M. Yuksel, Removal of nitrate from aqueous solution by nitrate selective ion exchange resins, Reac. Funct. Polym., 66 (2006) 1206-1214. http://doi.org/10.1016/j. reactfunctpolym.2006.03.009

[16] M. Chabani, A. Amrane, A. Bensmaili, Kinetic modelling of the adsorption of nitrates by ion exchange resin, Chem. Eng. J., 125 (2006) 111-117. http://doi.org/10.1016/j. cej.2006.08.014

[17] J.J. Schoeman, A. Steyn, Nitrate removal with reverse osmosis in a rural area in South Africa, Desalination, 155 (2003)15-26. http:// doi.org/10.1016/S0011-9164(03)00235-2

[18] M.I.M. Soares, Biological denitrification of groundwater, Water Air Soil Pollut.,123 (2000) 183-193. https://doi. org/10.1023/A:1005242600186

[19] A. Bhatnagar, M. Sillanpää, A review of emerging adsorbents for nitrate removal from water, Chem. Eng. J., 168 (2011) 493-504. http://doi.org/10.1016/j.cej.2011.01.103

[20] E.Y. Emori, F.H. Hirashima, C.H. Zandonai, C.A. Ortiz-Bravo, N.R.C. FernandesMachado, M.H.N. Olsen-Scaliante, Catalytic cracking of soybean oil using ZSM5 zeolite. Catal. Today, 279 (2017)168-176. http://doi. org/10.1016/J.CATTOD.2016.05.052.

[21] Q. Zhang. G. Liu. L. Wang. X. Zhang, G. $\mathrm{Li}$, Controllable decomposition of methanol for active fuel cooling technology, Energey Fuels, 28 (2014) 4431-4439. http://doi. org/10.1021/ef500668q

[22] W. Li, G. Li, C. Jin, X. Liu, J. Wang, One-step synthesis of nanorod-aggregated functional hierarchical iron-containing MFI zeolite microspheres. J. Mater. Chem. A, 3 (2015) 1478614793. http://doi.org/10.1039/C5TA02662H

[23] T.J. Pinnavaia, Intercalated clay catalysts, Sci., 220 (1983) 365-371. http://doi.org/10.1126/ science. 220.4595 .365

[24] K.G. Bhattacharyya, S.S. Gupta, Adsorption of a few heavy metals on natural and modified kaolinite and montmorillonite: a review, Adv. Colloid Interface Sci.,140 (2008) 114-131. http:// doi.org/10.1016/j.cis.2007.12.008

[25] S. Wang, Y. Peng, Natural zeolites as effective adsorbents in water and wastewater treatment, Chem. Eng. J., 156 (2010) 11-24. https://doi. org/10.1016/j.cej.2009.10.029

[26] B. Kamarehie, E. Aghaali, S.A. Musavi, S.Y. Hashemi, A. Jafari, Nitrate removal from aqueous solutions using granular activated carbon modified with Iron nanoparticles, Int. J. Eng. Transactions A, 31 (2018) 554-563. https:// doi.org/10.5829/ije.2018.31.04a.06

[27] M. Mazarji, B. Aminzadeh, M. Baghdadi, A. Bhatnagar, Removal of nitrate from aqueous solution using modified granular activated carbon, J. Mol. Liq., 233 (2017) 139-148. https:// doi.org/10.1016/j.molliq.2017.03.004

[28] L. Divband Hafshejani, A. Hooshmand, A.A. Naseri, A.S. Mohammadi, F. Abbasi, A. Bhatnagar, Removal of nitrate from aqueous solution by modified sugarcanebagasse biochar, Ecol. Eng., 95 (2016) 101-111. http://dx.doi. org/10.1016/j.ecoleng.2016.06.035

[29] T. Meftah, M. M. Zerafat, Nitrate removal from drinking water using organo-silane modified natural nano-zeolite, Int. J. Nanosci. Nanotechnol.,12 (2016) 223-232. http://www. ijnnonline.net/article_22931.html

[30] V. Alimohammadi, M. Sedighi, E. Jabbari, Response surface modeling and optimization of nitrate removal from aqueous solutions using magnetic multi-walled carbon nanotubes, J. Environ. Chem. Eng., 4 (2016) 4525-4535. http://dx.doi.org/10.1016/j.jece.2016.10.017

[31] A. Azari, A.H. Mahvi, S. Naseri, R. Rezaei 
Kalantary, M. Saberi, Nitrate removal from aqueous solution by using nodified clinoptilolite zeolite, research center for environmental pollutants, Arch. Hyg. Sci., 3 (2014) 21-29. http://jhygiene.muq.ac.ir

[32] S. Sepehri, M. Heidarpour, J. Abedi, Nitrate removal from aqueous solution using natural zeolite-supported zero-valent Iron nanoparticles, Soil Water Res., 9 (2014): 224-232. https://doi.org/10.17221/11/2014SWR

[33] E. Fataei, A. Seyyed Sharifi, H. Hasan Pour Kourandeh, A.S. Sharifi, S.T.S. Safavyan, Nitrate removal from drinking water in laboratory-scale using iron and sand nanoparticles, Int. J. Biosci.,10 (2013) 256-261. http://dx.doi.org/10.12692/ ijb/3.10.256-261

[34] A. Bhatnagar, E. Kumarb, M. Sillanpää, Nitrate removal from water by nano-alumina: characterization and sorption studies, Chem. Eng. J., 163 (2010) 317-323. https// doi/10.1016/j.cej.2010.08.008

[35] R.M. McKeown, C. Scully, T. Mahony, G. Collins, V. O'Flaherty, Long-term (1243 days), low-temperature (4-15C), anaerobic biotreatment of acidified wastewaters, bioprocess performance and physiological characteristics, Water Res., 43 (2009) 1611-1620. http://doi.org/10.1016/j. watres.2009.01.015

[36] C. Scully, G. Collins, V. O'Flaherty, Anaerobic biological treatment of phenol at 9.5-15 $\mathrm{C}$ in an expanded granular sludge bed (EGSB)-based bioreactor, Water Res., 40 (2006) 3737-3744. http://doi.org/10.1016/j. watres.2006.08.023

[37] J. Lopez, V.M. Monsalvo, D. Puyol, A.F. Mohedano, J.J. Rodriguez, Low temperature anaerobic treatment of lowstrength pentachlorophenol-bearing wastewater. Bioresour.Technol.,140 (2013) 349-356. http://doi.org/10.1016/j. biortech.2013.04.049

[38] W.M. Bandara, H. Satoh, M. Sasakawa, Y.
Nakahara, M. Takahashi, S. Okabe, Removal of residual dissolved methane gas in an upflow anaerobic sludge blanket reactor treating low-strength wastewater at low temperature with degassing membrane, Water Res.,45 (2011) 3533-3540. http://doi.org/10.1016/j. watres.2011.04.030

[39] A.J.M. Stams, C.M. Plugge, Electron transfer in syntrophic communities of anaerobic bacteria and archaea, Nat. Rev. Microbiol., 7 (2009) 568-577. http://doi.org/10.038/ nrmicro2166

[40] T. Tian, S. Qiao, C. Yu, Y. Yang, J. Zhou, Lowtemperature anaerobic digestion enhanced by bioelectrochemical systems equipped with graphene/PPy and $\mathrm{MnO}_{2}$ nanoparticles/ PPy-modified electrodes, Chemosphere,218 (2019) 119-127. http://doi.org/10.1016/j. chemosphere.2018.11.001

[SIP] SIP references (41-47s) have showed in supporting information page, http://journal. amecj.com/index.php/AMECJ-01 